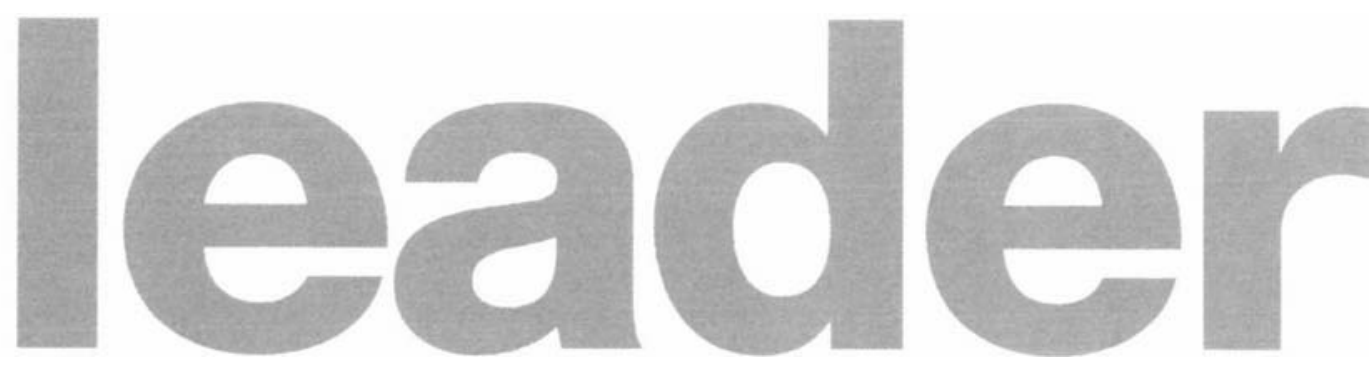

\title{
We can't have it both ways
}

The repercussions of the recent Research Assessment Exercise in UK universities rumble on. As readers of arq 7 will recall, research in architecture performed badly in comparison with other disciplines. No less than four contributions to this issue focus exclusively on matters relevant to both academia and practice internationally - raised by this outcome.

In the report section, Simon Pepper discusses the long-running question of whether design is research. Pepper is an architect turned architectural historian with extensive experience of arguing the case for design. His conclusions are a significant pointer towards the future exploitation of architectural practice in university architecture schools.

In the letters section, lan Cooper, an architect working as a building science researcher, considers the predicament facing both the architecture schools and practice. Writing from a construction industry perspective, he suggests that it is from government and industry inspired research that one can expect to gain most credit in the RAE. In his view, architectural practice and architecture schools haven't much to offer to this world of the 'top-down, big-business led approach to construction research and innovation'.

Back in the report section, William Mitchell, Dean of the School of Architecture and Planning at MIT, describes the methods by which some North American architecture schools ensure high academic standards. These seem both tougher and more tolerant than the increasingly centralised UK higher education system's somewhat insensitive RAE system. One wonders how American architecture schools would fare under Cooper's pragmatic, industry-orientated gaze.

But it is Frank Duffy's contribution to the letters pages which raises the most intriguing issues. First, the suggestion that architecture schools are being 'bullied into accepting categories and criteria which are very different from their own' and, second, the claim that 'excellent research work is being funded and carried out in practice'. In making these assertions, is Duffy, a practising architect with an outstanding track record both in research and thinking about it, on sound ground? 
On the first point, opinion is split. Duffy reflects the views of those unhappy with the RAE outcome. But, as Cooper makes clear in his letter, it takes a long time to build a robust research culture. Sadly, many UK architecture schools are at a disadvantage in this respect. Moreover, the criteria used in the recent RAE were perfectly reasonable - quality of publication, volume of funded research, numbers and progress of research students, research culture and leadership. What's wrong with these?

On the second point, Duffy - as a practitioner - speaks with authority. His own practice, DEGW International, frequently undertakes research for clients. But how much of the 'enormous amounts of data' which exist in it and other practices ever see the light of day? arq has approached many architectural practices with a reputation for their interest in research but only two (both with a base in academia) have ever submitted a paper for refereeing.

Are architectural practitioners just too busy to reflect on their work and develop a shared knowledge base? Are either they or their clients anxious to keep their research findings private? Is the sad truth that practices are more interested in being given six pages of colour photographs and 600 rather unprobing words of praise than in contributing 5000 words and 25 black and white images to a research journal? (Perhaps there's an opportunity here for academics to act as intermediaries - see p. 54). Or is this to be yet another area where architects claim to be doing something (design as research), but are not doing it well and transparently enough to deliver lasting benefits to their profession and society?

Answers, please. 